\title{
Educação Especial Inclusiva: uso de Recursos Educacionais Digitais nas Salas Multifuncionais
}

\author{
Special Education Inclusive: use of Digital Educational Resources in \\ Multifunctional Rooms
}

\section{Educación Especial Inclusiva: uso de Recursos Educativos Digitales en Salas Multifuncionales}

\author{
Arlete Vilela de Faria \\ Professora mestra da Secretaria de Estado de educação de Minas Gerais, MG, Brasil \\ E-mail: arletev.faria@gmail.com ORCID: https://orcid.org/0000-0001-7953-474X \\ Estela Aparecida Oliveira Vieira \\ Pós-doutora pela Universidade Federal de Lavras, Lavras, MG, Brasil \\ E-mail: estela.ap.o.vieira@gmail.com ORCID: https://orcid.org/0000-0002-2191-5918
}

Ronei Ximenes Martins

Professor doutor da Universidade Federal de Lavras, Lavras, MG, Brasil

E-mail: rxmartins@ufla.br ORCID: https://orcid.org/0000-0002-3586-9086

Recebido em 11 de dezembro de 2020

Aprovado em 24 de março de 2021

Publicado em 12 de abril de 2021

\section{RESUMO}

Este relato apresenta pesquisa que teve como objetivo investigar a aplicação de Recursos Educacionais Digitais por professores durante o atendimento educacional especializado realizado em Salas de Recursos Multifuncionais de escolas públicas do sul de Minas Gerais que contam com este recurso. A abordagem adotada foi quanti-qualitativa com coleta de dados por meio de questionário e entrevistas semiestruturadas com os professores participantes. Foram convidados 70 docentes das escolas estaduais de 29 cidades e 40 concordaram em participar. A partir da triangulação e análise dos dados, elementos essenciais que compõem a prática in loco da educação especial, foram identificados, dentre eles, a falta de diagnóstico de deficiência dos estudantes atendidos nas Salas de Recursos Multifuncionais. Outro ponto relevante identificado foi o déficit na formação inicial do profissional, que não aborda a temática em profundidade. Em consequência, a formação continuada se torna necessidade premente para a edificação do conhecimento tanto no campo da educação especial e inclusiva quanto das Tecnologias Digitais da Informação e Comunicação. Em relação à mediação e ao uso das tecnologias digitais, foram encontradas dissonâncias, pois, na maioria dos casos analisados, os recursos educacionais digitais não trouxeram alterações significativas na articulação entre ensino e conteúdo. Os resultados levaram à inferência de que existe necessidade de se estabelecer maior relação entre o currículo, os recursos tecnológicos disponíveis nas Salas de Recursos Multifuncionais, as demandas e peculiaridades dos estudantes e a mediação pedagógica do professor. 
http://dx.doi.org/10.5902/1984686X61433

Palavras-chave: Mediação Pedagógica; Educação Especial; Tecnologia Educacional; Tecnologia da Informação.

\section{ABSTRACT}

This paper is a research report that aimed to investigate the use of Digital Educational Resources by teachers in the Multifunctional Resource Rooms of public schools in Southern Minas Gerais that rely on this resource. The approach adopted was quantitativequalitative with data collection through a questionnaire and semi-structured interviews with the participating teachers. The 70 teachers from state schools in 29 cities were invited and 40 agreed to participate. From the triangulation and analysis of the data, essential elements that make up the in loco practice of special education were identified, among them, the lack of diagnosis of disability of the students attended in the Multifunctional Resource Rooms. Another relevant point identified was the deficit in the initial training of the professional, which does not address the theme in-depth. As a result, continuing education becomes a pressing need for the building of knowledge both in the field of special and inclusive education and digital information and communication technologies. Dissonances were found about mediation and the use of digital technologies. Perhaps because in most cases analyzed the digital educational resources didn't bring significant changes in the articulation between teaching and content. The results demonstrate to be necessary to establish a greater relationship between curriculum, technological resources available in the Multifunctional Resource Rooms, students demands and the pedagogical mediation of the teacher.

Keywords: Pedagogical Mediation; Special Education; Educational Technology; Information Technology.

\section{RESUMEN}

Este informe presenta investigaciones que tenían como objetivo investigar la aplicación de los Recursos Educativos Digitales por parte de los docentes durante la atención educativa especializada realizada en Salas de Recursos Multifuncionales de escuelas públicas del sur de Minas Gerais que dependen de este recurso. El enfoque adoptado fue cuantitativo-cualitativo con la recopilación de datos a través de un cuestionario y entrevistas semiestructuradas con los profesores participantes. Setenta profesores de escuelas estatales en 29 ciudades y 40 acordaron participar fueron invitados. A partir de la triangulación y análisis de los datos, se identificaron elementos esenciales que conforman la práctica in situ de la educación especial, entre ellos, la falta de diagnóstico de discapacidad de los estudiantes asistidos en las Salas de Recursos Multifuncionales. Otro punto relevante identificado fue el déficit en la educación inicial del profesional, que no aborda el tema en profundidad. Como resultado, la educación continua se convierte en una necesidad apremiante para la construcción del conocimiento tanto en el campo de la educación especial e inclusiva como en las tecnologías digitales de la información y la comunicación. En relación con la mediación y el uso de las tecnologías digitales, se encontraron disonancias, porque, en la mayoría de los casos analizados, los recursos educativos digitales no traían cambios significativos en la articulación entre la enseñanza 
http://dx.doi.org/10.5902/1984686X61433

y el contenido. Los resultados llevaron a la inferencia de que es necesario establecer una mayor relación entre el currículo, los recursos tecnológicos disponibles en las Salas de Recursos Multifuncionales, las demandas y peculiaridades de los alumnos y la mediación pedagógica del profesor.

Palabras clave: Mediación pedagógica; Educación Especial; Tecnología Educativa; Tecnología de la Información.

\section{Introdução}

A inclusão escolar é relativamente nova no sistema educacional brasileiro, o que gera necessidade de busca por estratégias que possibilitem sua efetivação de maneira eficiente $e$ eficaz. Atualmente, dentre as estratégias possíveis, encontra-se a inserção de Recursos Educacionais Digitais (RED) nas atividades de Atendimento Educacional Especializado (AEE). Acreditamos que as possibilidades trazidas pelos RED auxiliam às práticas educativas e somam uma maior inclusão e desenvolvimento das potencialidades dos estudantes com deficiência. Mas como a educação mediada por tecnologias digitais, onde os RED se enquadram, também é relativamente nova, nos resta questionar o papel do professor neste processo, sendo esta nossa questão de fundo. Acreditamos que a intencionalidade do agir docente quando mediado por tecnologias, enquanto estratégia de apropriação e construção do conhecimento, influencia o processo de ensino e aprendizagem, e, por isso, buscamos aqui meios para compreender como se dá a aplicação dos RED pelos professores no AEE de estudantes com deficiência em Salas de Recursos Multifuncionais de escolas públicas vinculadas a uma Superintendência Regional de Ensino do Sul de Minas Gerais.

A inclusão, que deve se dar por ações e também por meios, pode ser facilitada por tecnologias se estas se inter-relacionarem com a função social da escola, em favor dos estudantes. Desse cenário, não se abstém a formação de professores e a educação mediada pelas tecnologias digitais (TD) e essas questões levam à reflexão sobre os discursos da atual perspectiva educacional, que se alicerça em confrontos entre saberes, culturas e práticas (CANDAU, 2014). Se a escola está imersa em processos culturais globalizantes e de uso massivo de TDIC, esse fato a vincula à necessidade de tratar os artefatos tecnológicos digitais e seus usos como objetos de estudo e de suporte para ensinar/aprender.

Pensar estratégias de inclusão do estudante com necessidades especiais perpassa a necessidade de pesquisas que se dão no chão da escola, pois a universalização da educação com garantia de acesso e permanência proferida legalmente não assegura por si só um sistema inclusivo e muito menos a efetivação de uma educação significativa, ou seja, a 
http://dx.doi.org/10.5902/1984686X61433

aprendizagem. Para Giroto, Sabella e Lima (2019) o processo de inclusão está longe de se concretizar, pois necessita de mudanças paradigmáticas, atitudinais e metodológicas e não só de infraestrutura. Para as autoras é necessário repensar, também, o processo educativo como um todo, inclusive, o AEE. Estas mudanças, no âmbito institucional e pessoal, englobam métodos e recursos de ensino para que se consiga oferecer uma educação de qualidade.

Mantoan, Prieto e Arantes (2006, p. 18) já haviam observado, há mais de uma década, que as políticas educacionais confirmavam projetos igualitaristas, "repetindo que todos são "iguais", padronizando-os, negando "as condições que produzem as diferenças, que são as matrizes da nossa identidade". Mesmo que as políticas voltadas para estudantes com necessidades especiais tenham avançado, ainda não se pode falar realmente em inclusão. É importante constar que, nessa perspectiva de igualdade, a produção de recursos, estabelecimento de serviços e oportunidades idênticas e equivalentes para toda e qualquer pessoa, não leva em conta suas necessidades e especificidades. Pensando em equidade nesse contexto, trata-se, portanto, da constituição dos mesmos processos de forma adaptada, observando critérios de justiça, reconhecendo imparcialmente o direito específico e peculiar de cada um.

A inclusão como se dá hoje, é chamada por Valle e Connor (2014) de (in)visibilidade da deficiência, pois as barreiras invisíveis se prospectam falseando a inclusão, mas a realidade da autonomia e da independência ainda não se configura real para o sujeito como deveria. Tais concepções são resultado de muitos estudos e discussões, assim como a perspectiva da diversidade, da pluralidade e da inclusão que permeiam a educação.

Ao lado disso, considera-se que a educação contemporânea precisa responder às demandas dos educandos. São necessários processos de ensino e aprendizagem "que respeitem as diferenças, oferecendo o que não é próprio dos currículos da base nacional comum, mas próprio da realidade e do contexto do aluno" (MORAN, 1999, p. 2), e práticas fundamentadas na construção da identidade do educando. Esse deve, ou ao menos deveria ser, o princípio que norteia o processo de desenvolvimento psicossocial e pedagógico do AEE.

Portanto, faz-se necessário compreender o estabelecimento da ação do professor do AEE. $O$ agir docente deve se dar com base nas peculiaridades que o estudante apresenta $e$ seu contexto. O que quer dizer, na escolha dos recursos, meios, equipamentos, linguagens e conhecimentos que respondam a necessidade do estudante, assim como o apoio ao 
http://dx.doi.org/10.5902/1984686X61433

acesso e à participação ao ensino comum. Quando se propõe trabalhar com as diferenças e com a deficiência, são demandados processos, recursos e estratégias específicas para o estudante desenvolver suas potencialidades. Este agir docente, facilitado pela inclusão das TDIC, e novas formas de mediar o processo de aprendizagem trazem a necessidade de inovar práticas utilizadas até então.

Visto que são concepções pedagógicas e meios que se fundamentam em bases epistemológicas diferentes do ensino tradicional ${ }^{1}$, a prática docente voltada para a inclusão de novos sujeitos necessita ser observada mais de perto para que se possa entender e avaliá-la no contexto do AEE.

\section{O entrelace mediação, tecnologias digitais e atuação docente na Educação Especial}

Friedrich (2012, p. 190), uma estudiosa da mediação proposta por Lev Vigotski², declara que os instrumentos psíquicos são "meio de influência do sujeito sobre si mesmo", e mostra que todas as funções psíquicas superiores, "nascem usando instrumentos psicológicos e constituem consequência de fenômenos psíquicos mediados”. Na mediação pedagógica, o papel do professor vai além da compreensão e efetivação de meios para o desenvolvimento de funções psíquicas tais como a aprendizagem. Sua prática se fundamenta em escolhas conscientes e propositais dos objetivos e instrumentos mediadores que se apresentam como possibilidades de desenvolvimento e aprendizagem. No caso das TDIC, como instrumentos mediadores a possibilidade do lúdico, inerente a alguns artefatos, vai além de uma ferramenta lúdica e terapêutica. Pode ser um caminho de possibilidades e descobertas de si, do mundo e do outro, efetivando a aprendizagem e o desenvolvimento. O conhecimento de várias tecnologias e suas aplicações possibilitará ao professor especialista escolher a que mais se adequa aos objetivos de aprendizagem, de desenvolvimento e à realidade do estudante.

No caso da educação especial inclusiva, Giroto, Poker e Omote (2012) lembram que ela requer um professor preparado para desenvolver sua prática pedagógica, que considere diferentes modos de aprender e ensinar, pois são diferentes sujeitos com diferentes necessidades. De fato, o uso de Tecnologias digitais (TD) tem alcançado progressos na educação e são várias as tecnologias que contribuem para o desenvolvimento dos estudantes com deficiência - audiobooks, mouses adaptados, telas acessíveis, jogos de lógica - porém, é necessário avançar a discussão sobre a interrelação TD e a práxis, ou seja, 
http://dx.doi.org/10.5902/1984686X61433

se ocorre de forma dialógica e contribui significativamente para a construção do conhecimento e a autonomia do estudante.

Para além do direito de acesso, o uso de TDIC é apresentado também como um artefato ou um instrumento mediador do desenvolvimento social e cultural dos educandos na e para a sociedade em que estão inseridos. Mas, como explicita Coscarelli (2016, p. 26), "incorporar inovações nas instituições de ensino não é tarefa fácil, sejam elas tecnológicas ou não". Mesmo com as várias evoluções tecnológicas presentes, a incorporação das TD nas escolas públicas de educação básica não se deu e nem se dá atualmente de forma consistente (MARTINS; FLORES, 2017).

Os RED, instrumentos destinados a aprendizagem (FRANCO, 2013, p. 3), se pensados em uma acepção Vigotskiana, na qual o homem sócio histórico e cultural cria um número crescente de auxiliares externos - ferramentas, dispositivos, tecnologias - que sustentam processos psicológicos, tem sua importância amplificada na mediação pedagógica.

O desafio no uso dos RED, segundo Coscarelli (2016), é incluí-los sem perder dois importantes atributos: contextualização e emprego correto. Cabe ao professor se perguntar: Qual a interação necessária e momento ideal para esta intervenção? O professor precisa refletir sobre esta incorporação, conhecer as possibilidades de seu uso tanto como recurso didático como ferramenta de aprendizagem, sabendo reconhecê-las como meio. Os RED podem ser utilizados como instrumentos de/para mediação ou como meios/recursos didáticos para diversas estratégias de ensino conforme a práxis estabelecida por cada professor.

Todavia, seu emprego na educação tem se dado desvinculado de perspectivas interacionistas e de desenvolvimento integral de competências. As TD têm potencialidades expressas em suas múltiplas facetas, mas é importante conhecer suas possibilidades de uso primando pela descoberta. Nessa perspectiva, é preciso compreender a formação e o fazer docente relacionados à inserção das TDIC em seu contexto de trabalho. Como lembram Fernandes e Cunha (2013, p. 52), "a formação pode se configurar em múltiplas e diferentes dimensões, dependendo de onde se mira o objeto".

\section{Percurso metodológico}

A pesquisa se desenvolveu em uma abordagem quanti-qualitativa, tendo como instrumentos de obtenção de dados um questionário e a realização de entrevistas semiestruturadas com professores da rede de ensino público do Sul de Minas Gerais. A 
http://dx.doi.org/10.5902/1984686X61433

proposta foi submetida ao comitê de ética em pesquisa com seres humanos, que aprovou o projeto e os instrumentos de coleta dos dados ${ }^{3}$. Foram convidados 70 docentes de 108 escolas estaduais das 29 cidades que possuem Salas de Recursos Multifuncionais - SRM, lotados em uma Secretaria Regional de Ensino ao Sul do Estado de Minas Gerais. Aceitaram participar 40 professores. A definição das cidades se deu por conveniência, uma vez que estes foram convidados de maneira voluntária, assim tanto a localidade como a lotação não foram solicitadas para que os participantes não fossem identificados.

Quanto aos procedimentos, a fase de coleta de dados foi organizada em 2 etapas. A primeira, realizada entre fevereiro e março de 2019, foi a submissão do questionário eletrônico por meio de recurso disponível na internet, a partir de convite enviado por email aos docentes. Os endereços e nomes dos docentes foram fornecidos pela superintendência de ensino. No formulário, foi apresentado, inicialmente, o termo de consentimento livre e esclarecido que informava os detalhes da pesquisa. Se os participantes não concordassem com os termos, a coleta eletrônica era interrompida e nenhum dado armazenado. A análise destes dados permitiu a reorganização da etapa seguinte, a adequação do roteiro das entrevistas.

A segunda etapa consistiu na realização das entrevistas, in loco, com uma amostra aproximada de $20 \%$ dos participantes voluntários, respeitando o critério de saturação. As visitas às escolas seguiu um Roteiro de Entrevista, observando os objetivos da pesquisa, além da base teórica consolidada na revisão bibliográfica (LAKATOS; MARCONI, 2003). Esta etapa da pesquisa foi efetivada no mês de abril de 2019. O critério de inclusão do professor nesta amostra também se deu por conveniência, uma vez que participaram aqueles que se mostraram disponíveis para realizá-las de forma voluntária.

Os resultados da coleta foram analisados e relacionados com o referencial teórico a partir da triangulação de dados e de forma reflexivo-crítica. A triangulação, um recurso na investigação nas Ciências Sociais e Humanas, "reflete uma tentativa de assegurar uma compreensão em profundidade do fenômeno em questão" (DENZIN; LINCOLN, 2006, p. 19).

\section{Resultados e discussões}

A análise dos dados do questionário se deu por meio de estatística descritiva. A partir da identificação da predominância de evidências sobre os aspectos questionados, os relatos registrados nas entrevistas foram consultados e analisados para confirmação 
do que os dados quantitativos estavam apontando. A adesão dos participantes da pesquisa foi satisfatória para uma coleta por formulário eletrônico (VASCONCELOSGUEDES; GUEDES, 2007), contando com 40 professores de salas de recursos, o que corresponde a 57,14\% da população inicial prevista. Quanto às entrevistas, alcançaramse os $20 \%$ do universo de professores da regional em questão. A seguir, serão apresentados e discutidos os dados por tema abordado no questionário, já contrapostos aos dados das entrevistas.

\section{Atendimento nas salas de recursos multifuncionais}

Por meio da Política Nacional da Educação Especial na Perspectiva da Educação Inclusiva, em 2008 (BRASIL, 2008), foi estabelecida uma nova proposta de atendimento pedagógico especializado para estudantes com deficiências, transtornos globais do desenvolvimento/autismo e altas habilidades/superdotação. Nessa proposta, o AEE passou a ser oferecido, nas Salas de Recursos Multifuncionais (MILANEZ; OLIVEIRA; MISQUIATI, 2013), um espaço dotado de equipamentos, mobiliários e materiais didáticos para realização desse atendimento. Essa institucionalização do suporte ao estudante com deficiência é uma complementação ao ensino comum, de caráter obrigatório e gratuito em todos os níveis de ensino. Assim as SRM atendem, obrigatoriamente, às crianças a partir de quatro anos na pré-escola. A normativa que estabelece essa obrigatoriedade está em vigor há seis anos, e o projeto das SRM vigora há treze anos. No entanto, neste estudo o que chama a atenção é o fato de que somente $1 \%$ do AEE é efetivado na educação infantil estadual da regional estudada.

Tabela 1 - Nível de ensino de atuação dos Professores de Sala de Recursos Multifuncionais

\begin{tabular}{|l|c|c|c|c|}
\hline & $\begin{array}{c}\text { Educação } \\
\text { Infantil }\end{array}$ & $\begin{array}{c}\text { Ensino } \\
\text { Fundamental I }\end{array}$ & $\begin{array}{c}\text { Ensino } \\
\text { Fundamental II }\end{array}$ & $\begin{array}{c}\text { Ensino } \\
\text { Médio }\end{array}$ \\
\hline $\begin{array}{l}\text { Atuam Somente Neste } \\
\text { Nível }\end{array}$ & 0 & 9 & 6 & 2 \\
\hline $\begin{array}{l}\text { Atuam em Mais de um } \\
\text { Nível }\end{array}$ & 1 & 11 & 23 & 18 \\
\hline $\begin{array}{l}\text { Total de professores por } \\
\text { nível de atuação }\end{array}$ & 1 & 20 & 29 & 20 \\
\hline
\end{tabular}

Fonte: Dados da pesquisa (2019). 
http://dx.doi.org/10.5902/1984686X61433

Em contrapartida, outros estudos demonstram um resultado mais elevado neste atendimento, como a pesquisa desenvolvida por Rocha e Fernandes (2017), que apresenta que $46 \%$ dos municípios pesquisados possuem salas de recursos na Educação Infantil. Essa discrepância, talvez, possa ser justificada pela organização do sistema educacional brasileiro, no qual a educação infantil é, geralmente, de responsabilidade da esfera municipal e este estudo se limitou às escolas estaduais.

Quanto ao número de estudantes por sala de aula, fator relevante para a qualidade do trabalho com estudantes com deficiência, pode ser observado que $30 \%$ das SRM pesquisadas estão no seu limite de operacionalização: $20 \%$ dos professores entrevistados atendem até 15 estudantes, outros $20 \%$ até 20 estudantes, 30\% atendem até 25 estudantes, $25 \%$ até 30 estudantes e os 5\% restantes atendem acima de 30 estudantes, o que dificulta a prática especializada. De acordo com o documento Guia da Educação Especial na rede estadual de ensino de Minas Gerais (MINAS GERAIS, 2014), o professor de sala de recursos pode atender de 15 a 30 estudantes, organizados em grupos de atendimento individual ou coletivo, conforme afinidades das necessidades educativas e potencialidades. Outras pesquisas apontam que este número não deve ultrapassar 20 estudantes (MUNHOZ et al, 2017; SANTOS et al, 2017; SILVA; VELANGA, 2015).

Sabe-se que as discussões a respeito do número excessivo de estudantes em sala de aula já se desgastam no debate educacional (NETO; BIEGING; BUSARELLO, 2020; PIMENTA, 2019; PINTOCO, 2017; BELLO, 2002; GERSDORFF, 1981), e isso não é diferente no AEE/SRM. De um lado, a concepção de que a quantidade de estudantes tem influência no processo de aprendizagem e de outro a concepção de que a qualidade do ensino não é justifica pela quantidade, mas pelos métodos ou processos pedagógicos. No entanto, devemos levar em consideração que o atendimento em SRM para ser especializado, requer uma atenção particular às necessidades próprias de cada estudante.

Quanto à infraestrutura disponível, verificou-se que 97,5\% das SRM analisadas possuem computadores e que $95 \%$ possuem acesso à internet e em relação ao conhecimento para trabalho com a informática na educação, 70\% dos professores consideram seus conhecimentos na área de informática como bons. Apesar dos dados quantitativos demonstrarem a existência de artefatos e, em tese, conhecimento técnico para utilizá-los, quando verificados os dados das entrevistas, a infraestrutura se apresentou deficitária e a capacitação docente está entre os maiores obstáculos para 
http://dx.doi.org/10.5902/1984686X61433

efetivação do uso desses recursos no processo educativo. O que se pode perceber, é que a percepção de conhecimento do uso do computador dos professores se resume ao uso instrumental, o que gera uma utilização não adequada enquanto recurso pedagógico.

Esta dicotomia entre fatos e percepções não é exclusiva dos ambientes destinados à inclusão. Silva (2019), em sua pesquisa sobre inserção de tecnologias digitais da informação em comunicação em escolas públicas municipais, identificou fenômeno semelhante. Porém, este estudo não apresenta dados suficientes para responder a contradição apresentada. Um dos fatores que podem ser apontados é a necessidade de uma formação voltada para o uso de tecnologias aplicado ao AEE.

\section{Professores: perfil e formação}

A experiência é importante para a construção da identidade do professor, de seus saberes e práticas. Tardif e Raymond (2000) avançam, ao afirmar que a apropriação do saber docente é construída pelo tempo, pelas experiências e conhecimentos adquiridos antes e durante o exercício da profissão. Os dados quantitativos da pesquisa apontam que 53,6\% dos professores do AEE possuem menos de 2 anos de atuação nas salas de recursos multifuncionais. Esses profissionais ainda se encontram em processo de construção de sua identidade profissional. Isto também aparece no discurso dos professores pesquisados, que apontam insegurança e incertezas na forma como devem conduzir suas intervenções em alguns momentos.

Verificou-se, também, uma precarização na formação inicial de professores na área da educação especial e de tecnologias da informação e comunicação. Esta posição se pauta na evidência dos dados que apontaram que $58 \%$ dos pesquisados declararam não ter disciplinas na graduação com a temática educação especial inclusiva e 35\% não tiveram disciplinas na temática na TDIC. E mesmo que possuam a educação continuada, pois $95 \%$ dos profissionais possuem especialização e $5 \%$ cursos de aperfeiçoamento na área de Educação Especial ou Educação Inclusiva e 80\% em cursos na área de tecnologias da informação, estes não se sentem seguros no uso de RED aplicada a SRM. Sendo que $62 \%$ conheceram os RED em cursos e $32 \%$ em sua vivência escolar, $7 \%$ não responderam. Na maioria dos casos, eles caracterizaram a formação em RED como instrumental e técnica. Desta forma, vê-se uma necessidade de qualificação no âmbito de suas práticas, uma vez que a mediação dos instrumentos pedagógicos se realiza no agir, nas particularidades de cada indivíduo durante o atendimento. 
http://dx.doi.org/10.5902/1984686X61433

É relevante destacar que nas entrevistas a maioria dos professores confundiram os conceitos de tecnologia assistiva e de TD. As Tecnologias Assistivas (TA) fazem uso de recursos digitais, estes oferecem uma gama de ferramentas e elementos de auxílio à superação de barreiras, o que não quer dizer que todas as TD são TA ou vice versa, mas sim que existem recursos digitais que podem ser utilizados no auxílio da aprendizagem. Entretanto, quando questionados sobre o tipo de formação em TD, 80\% apontaram cursos de TA como sendo de TD. O que demonstra uma confusão conceitual quanto ao uso assistivo amplo das TD do uso educacional específico.

Isso não quer dizer que a formação continuada foi ineficaz, ao contrário possibilitou melhor fundamentação para a prática docente. Grande parte destes, $64 \%$ confirmam que a formação continuada em educação especial inclusiva permitiu maior aprofundamento dos conceitos e aprimoramento da sua práxis e $69 \%$ observaram o mesmo para as formações em TD, em consonância com o percentual de professores que declararam ter conhecimento para trabalho com a informática na educação, $70 \%$. No entanto, na entrevista a maioria afirma que a formação em TD foi insuficiente. O que se percebe, então, é a demanda por formação que problematize a realidade, que faça esta interlocução entre a teoria e a prática, apresentando um diálogo mais significativo entre o contexto e seus objetivos, articulado ao conteúdo. A questão que permanece e que demandará investigação mais aprofundada é: Há necessidade de competência específica na dimensão instrumental e de mediação pedagógica com uso de TDIC neste contexto?

Quanto aos desafios e dificuldades nesse campo, a falta de incentivo à formação continuada foi destacada pelos professores, sendo que $37 \%$ dos professores observaram isso no âmbito da Educação Especial Inclusiva, e 57\% no caso das TDIC. Um estudo desenvolvido pelo Consulting Group e Instituto Ayrton Senna [BCG \& IAS] (2014), aponta esta necessidade ao retratar a carência de incentivos formais à formação continuada como um dos seis obstáculos a serem superados para o favorecimento da capacitação de docentes.

\section{Perfil dos estudantes sob a ótica dos professores}

O desenvolvimento do estudante com deficiência, TGD e altas habilidades é o objetivo do $\mathrm{AEE}$, assim ao se propor um estudo que aborde o uso de recursos educacionais digitais seu público alvo não poderia estar de fora, visto que as práticas sofrem influência direta conforme as particulares de seu público. Portanto, para 
apresentar o contexto de trabalho do professor do AEE e do seu agir docente, procurouse apresentar aqui o perfil do estudante atendido. A pesquisa revelou que tanto estudantes sem diagnóstico quanto os que estão fora do perfil do público-alvo das salas multifuncionais, por exemplo, os transtornos funcionais específicos, totalizando $77 \%$, são atendidos nesses espaços.

Os dados certificam o fato de que 19\% das SRM atende mais estudantes fora do perfil do público alvo estipulados em Lei, do que estudantes com deficiência, TGD e altas habilidades (BRASIL, 2017; BRASIL, 2015). O dissenso sobre o perfil a ser atendido nas salas de recursos especializados inicia-se no texto da Lei de Diretrizes e Bases da Educação - LDB e da Política Nacional da Educação Especial na Perspectiva da Educação Inclusiva.

Estas se contradizem quanto à organização e sistematização de conceitos, pois há divergência na proposição do público da educação especial na perspectiva inclusiva, e a dificuldade recai sobre o professor.

Por um lado, a LDB prevê AEE "gratuito aos educandos com deficiência, transtornos globais do desenvolvimento e altas habilidades ou superdotação, transversal a todos os níveis, etapas e modalidades, preferencialmente na rede regular de ensino" (BRASIL, 2017, p. 8). Por outro lado, a versão atual da Política Nacional da Educação Especial na Perspectiva inclusiva de 2014 acrescenta "em outros, como os transtornos funcionais específicos, a educação especial atua de forma articulada com o ensino comum, orientando para o atendimento desses estudantes". Portanto, esta última introduzia a possibilidade de atendimento fora do escopo estabelecido pela $L D B$, a favor de maiores condições inclusivas e de equidade no campo educacional, reconhecendo a necessidade do atendimento a transtornos funcionais específicos. Esta contradição sugere a necessidade de redefinição das políticas, pois interfere diretamente na prática do professor. Referida incompatibilidade foi resolvida com a promulgação da Nova Política Nacional de Educação Especial: Equitativa, Inclusiva e com Aprendizado ao Longo da Vida (BRASIL, 2020), que esclarece que seu público alvo são alunos com deficiência, TGD e altas habilidades.

\section{Práxis do professor e a mediação por TDIC}

O ato pedagógico se concretiza na intersecção professor/estudante/mediação. Esta mediação é um processo de construção de saber, individual e coletivo e pode acontecer 
também pela interação digital, dinâmica e construtiva, no entanto, não deve ter por base o tecnicismo. Masetto (2013, p. 165) lembra que "as riquezas de recursos nem de longe deverão substituir a presença e a ação do professor com os estudantes. Essas técnicas e ambientes tecnológicos deverão colaborar para ações conjuntas de professor e estudante". Ao responderem ao questionamento sobre fazer ou não a mediação pedagógica e a adaptação curricular à necessidade do estudante, $95 \%$ dos docentes entrevistados responderam que sim, demonstrando que o fazer é compatível com o referencial teórico que destacamos. As entrevistas revelaram nuances mais específicas, pois alguns consideram essa mediação como acompanhamento do estudante enquanto este acessa as atividades propostas, outros veem como momento de autonomia, o qual deve ser realizado de forma independente para a construção do conhecimento. Não houve um consenso em como devem ser realizadas, isto pode ser justificado pela particularidade de cada caso, porém, não houve manifestação sobre como poderia ser problematizado com o próprio estudante. Os RED quando inseridos como recursos didáticos possibilitam a elaboração de conhecimentos por meio de interações e descobertas (SILVA; LIMA, 2010; SILVA, 2009), e podem assumir a perspectiva Vigotskiana de instrumentos mediadores.

Especificamente quanto ao uso dos RED na prática docente, foi possível perceber que se trata de um meio auxiliar, funcionando mais como uma 'atividade de fixação' ou 'complementar', termo utilizado pelos próprios docentes. Observou-se que essa atividade é descentralizada e desarticulada do planejamento pedagógico, não provocando alterações na estrutura do ensino e na articulação entre conteúdo e prática. Quando utilizado na prática, o computador se destacou mais que o professor no papel de instrumento mediador da aprendizagem, entre eles o uso dos JED - Jogos educacionais digitais. Giroto, Poker e Omote (2012, p. 20) reforçam o fato de que as TDIC são "um conjunto de ferramentas colocadas à disposição do ensino que podem contribuir efetivamente na mediação significativa entre o estudante e o conhecimento", mas, por si mesmas não garantem a sua escolarização. 
http://dx.doi.org/10.5902/1984686X61433

Tabela 2 - Relação entre uso de recursos na SRM e objetivos apontados em sua aplicação segundo os professores de $A E E-\mathrm{N}=40$

\begin{tabular}{|c|c|c|c|c|c|c|c|}
\hline Recursos & $\mathrm{CA}$ & TA & Alfabetização & Letramento & $\begin{array}{l}\text { JP } \\
\text { concretos }\end{array}$ & $\begin{array}{l}\text { JP } \\
\text { Digitais }\end{array}$ & $\begin{array}{l}\text { Outras } \\
\text { TD }\end{array}$ \\
\hline Utilizam & $70 \%$ & $67,50 \%$ & $82,50 \%$ & $85 \%$ & $97,50 \%$ & $82,50 \%$ & $62 \%$ \\
\hline e enquadram & $73 \%$ & $74 \%$ & $61 \%$ & $65 \%$ & $61 \%$ & $49 \%$ & \\
\hline Não se enquadram & 0 & $2 \%$ & $9 \%$ & $9 \%$ & $21 \%$ & $21 \%$ & 0 \\
\hline Não responderam quais & $27 \%$ & $24 \%$ & $30 \%$ & $26 \%$ & $28 \%$ & $30 \%$ & 0 \\
\hline Objetivos se enquadram & $43 \%$ & $48 \%$ & $42 \%$ & $47 \%$ & $36 \%$ & $33 \%$ & $83 \%$ \\
\hline $\begin{array}{l}\text { Objetivos não se } \\
\text { enquadram }\end{array}$ & 0 & $4 \%$ & $9 \%$ & $9 \%$ & $20 \%$ & $21 \%$ & 0 \\
\hline $\begin{array}{l}\text { Não responderam quais } \\
\text { objetivos }\end{array}$ & $57 \%$ & $48 \%$ & $49 \%$ & $44 \%$ & $44 \%$ & $46 \%$ & $17 \%$ \\
\hline
\end{tabular}

Nota: $\mathrm{CA}=$ Comunicação alternativa; $\mathrm{TA}=$ Tecnologias assistivas; $\mathrm{JP}=$ Jogos pedagógicos; $\mathrm{TD}=$ Tecnologia Digital

Fonte: Dados da pesquisa (2019).

Os dados gerais demonstram que os professores inserem as TDIC no processo pedagógico, o problema se funda em como são utilizadas. As respostas coletadas no questionário sobre o objetivo de uso das tecnologias na SRM, como demonstrado na tabela 2, em sua maioria estão de acordo com a indicação, no entanto ao serem entrevistados percebeu-se que esses são utilizados de maneira complementar. Este uso detectado nas respostas dos docentes coloca os RED como um apêndice do processo de ensino, ou seja, uma aplicação que necessita ser mais bem planejada. Sendo necessário vincular a intencionalidade a mediação e especificidade do estudante. Portanto, não podemos afirmar que foram identificadas evidências de transformação real da prática em favor da inclusão a partir da inserção de RED como instrumentos de mediação.

Verificou-se que $62,5 \%$ dos professores entrevistados baseiam o planejamento e as práticas conforme necessidades específicas de cada deficiência, já 37,5\% constroem seu planejamento a partir das dificuldades pedagógicas nas séries em que estão inseridos. Neste quesito há uma carência de definição de como o professor deve proceder no AEE. Para Malheiro e Mendes (2017, p. 109) esta ora se centra em aspectos determinantes da deficiência e ora em processos escolares. Por mais que isto permita uma intervenção 
http://dx.doi.org/10.5902/1984686X61433

conforme a demanda percebida, a falta de orientação constatada gera incertezas na prática, podendo ter impactos diferenciados em cada um conforme à realidade vivenciada.

\section{Considerações finais}

A incorporação de RED na educação especial, assim como o AEE, apresenta-se como uma área relativamente nova na educação. Por consequência, ambas apresentam dificuldades próprias, e, ao serem combinadas, estas dificuldades se potencializam, o que evidencia a necessidade de estudos que contemplem os novos sujeitos e contextos que a compõe. O professor passa a ter um papel diferenciado que demanda dele novas habilidades, pois, na mediação pedagógica o professor precisa compreender as necessidades específicas do educando e seu estágio de desenvolvimento para oferecer possibilidades de maturação de suas potencialidades e responder às demandas escolares. Isso significa que a prática docente deve se fundamentar em escolhas conscientes e propositais, vinculadas a objetivos prévios e instrumentos mediadores que se apresentem como possibilidades de desenvolvimento e aprendizagem.

Ao ser analisada mais de perto, a ação docente demonstrou fragilidades e incongruências intrínsecas de uma prática docente que não se sustenta de maneira eficiente pela vulnerabilidade de suas bases estruturais. O primeiro ponto que pode ser destacado é a própria legislação que se contradiz em suas normativas primas, a Lei de Diretrizes e Bases da educação - LDB e a Política nacional da educação especial, levando as secretarias a trabalharem no limite de sua operacionalização. $O$ mérito deste trabalho não é discutir se estudantes que fogem do escopo de atendimento proposto devem ou não ser atendidos, mas pontuar que a falta de coerência na legislação gera uma sobrecarga em muitas unidades, dificultando um atendimento mais qualificado. Junta-se a isso a qualidade da infraestrutura e a capacidade técnica para lidar com RED ser deficitária. São professores que iniciaram há pouco a carreira na educação especial, inseguros em suas condutas e com formação precária na área de TD aplicadas à educação especial.

Foi observado a demanda de uma formação que estabeleça um diálogo entre a teoria e a prática. Os RED não são explorados em toda sua potencialidade no desenvolvimento da aprendizagem, e em alguns casos são empregados de maneira tal que o objetivo da tecnologia não corresponde ao objetivo de aprendizagem. $O$ uso ainda se dá de maneira superficial e fragmentada, isto se deve a questões que vão desde a formação até a 
http://dx.doi.org/10.5902/1984686X61433

apropriação para o uso, passando por questões epistemológicas e desaguando em uma prática de cunho mais tecnicista do que centrado na realidade dos estudantes.

Assim, a problemática da inclusão segue permeada pela contradição legislativa que não define de maneira clara o público alvo, também pela formação ainda insatisfatória. A falta de consenso sobre a prática suscita necessidade de pesquisas aproximarem-se da realidade, que se discuta a/com a prática. Há um descompasso entre planejamento e objetivo de ensino; os recursos e suas funções; e entre o que o professor quer ensinar e o que o estudante precisa aprender, é importante visar a aprendizagem como meio para a promoção da igualdade e equidade, eliminando práticas tradicionalistas que não visualizam as necessidades do sujeito e da sociedade.

As tecnologias são um desafio para a prática pedagógica, mas ela amplia possibilidades e apresenta outros sentidos para a aprendizagem, reinventa a prática docente e a função da escola. A educação denominada inclusiva tem se demonstrado ainda excludente, os problemas são 'mascarados' e as possíveis soluções procrastinadas ano a ano. Até que ponto o sistema educacional tem sido, de fato, inclusivo?

\section{Referências}

Boston Consulting Group (BCG); Instituto Ayrton Senna (IAS). Formação continuada de professores no Brasil: Acelerando o desenvolvimento dos nossos educadores. São Paulo, 2014.

BRASIL. LDB - Lei de Diretrizes e Bases da Educação Nacional: lei no 9.394, de 20 de dezembro de 1996, que estabelece as diretrizes e bases da educação nacional. 14. ed. Brasília: Câmara dos Deputados, 2017a. 26 p. (Série Legislação, no 263).

BRASIL. BNCC. Base Nacional Comum Curricular - Ensino Fundamental. Ministério da Educação / Secretaria de Educação Fundamental. - Brasília: MEC/SEB, 2017.

BRASIL. Decreto № 10.502, de 30 de Setembro d 2020, que Institui a Política Nacional de Educação Especial: Equitativa, Inclusiva e com Aprendizado ao Longo da Vida. Brasília: 2020.

BRASIL. Política Nacional de Educação Especial na perspectiva da educação inclusiva. Brasília: MEC/SEESP, 2014. 15 p.

BRASIL. Política Nacional de Educação Especial na perspectiva da educação inclusiva. Brasília: Ministério da Educação, 2008. 19 p. (Documento elaborado pelo

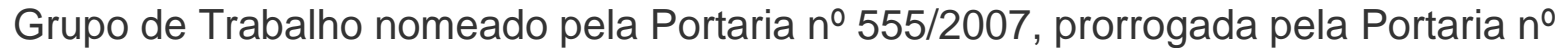
948/2007, entregue ao Ministro da Educação em 07 de janeiro de 2008). 
BRASIL. LBI. Lei no 13.146, de 6 de julho de 2015. Institui a Lei brasileira de inclusão da pessoa com deficiência (Estatuto da pessoa com deficiência). Diário Oficial d União, Brasília, DF, 7 jul. 2015.

CANDAU, V. M. F. Ser professor/a hoje: novos confrontos entre saberes, culturas e práticas. Educação, Porto Alegre, v. 37, n. 1, p. 33-41, jan./abr. 2014.

COSCARELLI, C. V. Tecnologias para aprender. São Paulo: Parábola Editorial, 2016. $192 \mathrm{p}$.

DENZIN, N.K.; LINCOLN, Y.S. 2006. O planejamento da pesquisa qualitativa. Porto Alegre, Penso, $432 \mathrm{p}$.

FERNANDES, C. M. B.; CUNHA, M. I. Formação de professores: tensão entre discursos, políticas, teorias e práticas. Inter-Ação, Goiânia, v. 38, n. 1, p. 51-65, jan./abr. 2013.

FRANCO, C. C. C. A utilização de recursos educativos digitais na sala de aula: um componente fundamental no ensino? 2013. 92 p. Dissertação (Mestrado em Ensino da História e da Geografia) - Universidade Nova de Lisboa, Portugal, 2013.

FRIEDRICH, J. Lev Vigotski: mediação, aprendizagem e desenvolvimento: uma leitura filosófica e epistemológica. Campinas: Mercado de Letras, 2012. 128 p.

GIROTO, C. R.; POKER, R. B.; OMOTE, S. (Org.). As tecnologias nas práticas pedagógicas inclusivas. Marília: Oficina Universitária, 2012. 238 p.

LAKATOS, E. M.; MARCONI, M. A. Fundamentos de metodologia científica. 5. ed. São Paulo: Atlas, 2003. 363 p.

MALHEIRO, C. A. L.; MENDES, E. G. Sala de recursos multifuncionais: formação, organização e avaliação. Jundiaí: Paco, 2017. 244 p.

MANTOAN, M. T. E.; PRIETO, R. G.; ARANTES, V. A. Inclusão escolar: contos e contrapontos. São Paulo: Summus, 2006. 103 p.

MARTINS, R.X.; FLORES, V. F. Era uma vez o Proinfo... diferenças entre metas e resultados em escolas públicas municipais. Horizontes, v. 35, n. 2, p. 17-26, 2017. Disponível em: https://revistahorizontes.usf.edu.br/horizontes/article/view/319 (Acesso em 25 de fevereiro de 2020).

MASETTO, M. T. Mediação pedagógica e tecnologias de informação e comunicação. In: MORAN, J. M.; MASETTO, M. T.; BEHRENS, M. A. Novas tecnologias e mediação pedagógica. Campinas: Papirus, 2013. p. 133-173. (Coleção Papirus Educação).

MILANEZ, S. G. C.; OLIVEIRA, A. A. S.; MISQUIATTI, A. R. N. Atendimento educacional especializado para alunos com deficiência intelectual e transtornos globais do desenvolvimento. São Paulo: Cultura Acadêmica, 2013. 144 p.

MINAS GERAIS. Secretaria de Estado de Educação. Guia de orientação da Educação Especial na rede estadual de ensino de Minas Gerais. Belo Horizonte: SEE, 2014. 25 p. 
http://dx.doi.org/10.5902/1984686X61433

MORAN, M. O uso das novas tecnologias da informação e da comunicação na EAD: uma leitura crítica dos meios. São Paulo: USP, 1999. 8 p. (Palestra realizada pela COPEAD/SEED/MEC)

MUNHOZ, D. J. et al. A oferta do atendimento educacional especializado e serviços de apoio na abrangência do núcleo regional de educação de Londrina-PR. In: SEDU SEMANA DA EDUCAÇÃO, 17., 2017, Londrina. Anais... Londrina: Universidade Estadual de Londrina, 2017.

ROCHA, L. M.; FERNANDES, S. A oferta do atendimento educacional especializado nos municípios da área metropolitana norte de Curitiba, no contexto da política nacional de educação especial, na perspectiva da educação inclusiva. InterMeio, Campo Grande, v. 23, n. 45, p. 229-253, jan./jun. 2017.

SANTOS, J. O. L. et al. Atendimento educacional especializado: reflexões sobre a demanda de alunos matriculados e a oferta de salas de recursos multifuncionais na rede municipal de Manaus-AM. Revista Brasileira de Educação Especial, Marília, v. 23, n. 3, p. 409-422, jul./set. 2017.

SAVIANI, D. Escola e democracia. 24. ed. São Paulo: Cortez, 1991.

SILVA, L. M. Educação inclusiva e formação de professores. Cuiabá: Instituto Federal de Educação, 2009. $90 \mathrm{p}$

SILVA, G. G. R. Diagnóstico da inserção de tecnologias educacionais em escolas de ensino fundamental do interior de Minas Gerais. 2019. 149 p. Dissertação (Mestrado Profissional em Educação) - Universidade Federal de Lavras, Lavras, 2019.

SILVA, S. C. G. C.; VELANGA, C. T. Formação inicial e continuada dos professores da sala de recurso multifuncional: o desafio da inclusão. In: CONGRESSO NACIONAL DE EDUCAÇÂO, 12., 2015, Curitiba. Anais... Curitiba: Secretaria da Educação, 2015. p. 25216-25332.

SILVA, B.; LIMA, J. C. Utilização de recursos digitais nas aulas de apoio educativo introduzindo processos metacognitivos e de auto-regulação das aprendizagens. In: COLÓQUIO SOBRE QUESTÕES CURRICULARES, 11; COLÓQUIO LUSO BRASILEIRO: DEBATER O CURRÍCULO E SEUS CAMPOS: POLÍTICAS, FUNDAMENTOS E PRÁTICAS, 5., 201, Porto. Anais... Porto: Faculdade de Psicologia e Ciências da Educação, 2010. p. 4374-4387.

TARDIF, M.; RAYMOND, D. Saberes, tempo e aprendizagem do trabalho no magistério. Educação \& Sociedade, Campinas, v. 21, n. 73, p. 209-244, dez. 2000

VALLE, J. W.; CONNOR, D. J. Ressignificando a deficiência: da abordagem social às práticas inclusivas na escola. Porto Alegre: AMGH, 2014. 240 p.

VASCONCELLOS-GUEDES, LILIANA; GUEDES, LUIS FERNANDO ASCENÇÃO. surveys: Vantagens e limitações dos questionários eletrônicos via internet no contexto da pesquisa científica1. X SemeAd-Seminário em Administração FEA/USP (São Paulo, Brasil), p. 84, 2007. 
http://dx.doi.org/10.5902/1984686X61433

VIGOTSKI, L. A formação social da mente. São Paulo: Martins Fontes. 2007. 184 p.

NETO, Alaim Souza; BIEGING, Patricia; BUSARELLO, Raul Inácio. O que é ser professor? São Paulo: Pimenta Cultural, 2020. 266p..

PIMENTA, Jussara Santos. Docência, Formação e Práticas Pedagógicas: Experiências e Pesquisas. Paco e Littera, 2019. 232 p..

PINTOCO, Vanessa Moreira. Visão do professor sobre o número de alunos por turma: uma contribuição para a melhoria da qualidade da educação. 2017. Dissertação (Mestrado em Estudos Profissionais Especializados em Educação) - Politécnico de Porto. Porto, 2017.

\section{BELLO, Isabel Merelo. Formacao de Professores Profissionalidade E Pratica}

Docente. São Paulo: Arte \& Ciência, 2002. 212 p..

GERSDORFF, Ralph von. Educação brasileira: problemas e soluções possíveis. São Paulo: Agir Editora, 1981. 171 p.

\section{Notas}

${ }_{1}^{1}$ Para Saviani (1991) o ensino tradicional se estruturou através do método pedagógico expositivo, e tem como objetivo a transmissão de conhecimentos, na qual o professor domina os conteúdos logicamente organizados e estruturados para serem transmitidos aos alunos, que são elementos passivos na sala de aula. Tinha como premissa a universalização do acesso ao conhecimento, promovendo uma formação puramente moral e intelectual, para a convivência social.

${ }^{2} \mathrm{O}$ uso da grafia Vigotski é encontrado na literatura de língua portuguesa e Vigotski na língua inglesa. No Brasil, com a entrada da letra $Y$ na última reforma ortográfica, muitos cientistas optaram por espelhar as traduções norte-americanas. Optamos por manter a grafia Vigotski no presente texto.

${ }^{3} \mathrm{O}$ projeto de pesquisa foi submetido e aprovado pelo comitê de ética em 15/12/2017, conforme Parecer no 2.442.256. 